\title{
Drug delivery to the eye: what benefits do nanocarriers offer?
}

Ocular drug delivery has seen several advances in the past few decades, with respect to new drugs, improved formulations, targeted delivery, as well as exploration of new routes of drug administration. New materials have been explored for encasing existing drugs, which can enhance treatment by increasing bioavailability, decreasing toxicity, providing better tissue adherence, targeted delivery as well as increased duration of action. The challenges and requirements are different for the anterior and posterior ocular segments. This review summarizes the recent advances in sustained ocular therapy, both to the anterior and posterior segments, which have been made possible, thanks to nanotechnology. We also discuss the distribution and fate of these nanocarriers themselves, postadministration, as well as clearance from ocular tissues.

First draft submitted: 28 October 2016; Accepted for publication: 10 January 2017; Published online: 10 February 2017

Keywords: anterior segment delivery $\bullet$ fate and ocular disposition • liposomes

- nanoparticles • posterior segment delivery • sustained delivery

The eye is an anatomically and physiologically unique sensory organ. The eye can broadly be classified into two main regions: the anterior segment, which is the front onethird of the eye between the cornea and the lens, and the posterior segment, which is the back two-thirds of the eye from the lens to the optic nerve, including the vitreous humor.

There are several chronic and acute diseases which can affect the anterior as well as posterior segment of the eye, and in some cases lead to sight-threatening conditions. In developed nations, posterior ocular segment diseases such as age-related macular degeneration (AMD), diabetic macular edema (DME) and diabetic retinopathy together are the leading causes of vision loss. By 2050, it is projected that vision loss will grow to affect more than 10 million people, from the current statistic of 4.4 million. The total prevalence of cataract, diabetic retinopathy, glaucoma and AMD is expected to increase to nearly 70 million adults by 2050 . Of this, around 17.8 million cases are projected to be from early-stage AMD [1]. Some of the common chronic anterior segment diseases are glaucoma, uveitis, cataract, etc., of which cataract itself accounts for about $51 \%$ of blindness, based on a 2010 survey [2,3].

The eye has several protective barrier layers that render it impervious to potentially harmful substances, microorganisms and toxins. These barriers, which are critical in preserving and maintaining vision, also prevent the entry and diffusion of drug molecules to the ocular tissues. Thus ocular drug delivery, especially for extended durations, is particularly challenging as these barriers effectively screen, limit and clear away the formulations.

For most diseases of the anterior segment, topical instillation of eye drops is the preferred and conventional route of treatment. However, it is associated with limitations such as poor patient compliance, limited penetration to tissue of interest, the need for
Rini Rachel Joseph ${ }^{1}$ \& Subbu S Venkatraman ${ }^{*, 1,2}$

'School of Materials Science \& Engineering, Nanyang Technological University, Singapore 639798, Singapore ${ }^{2}$ NTU-Northwestern Institute for Nanomedicine, School of Materials Science \& Engineering (MSE), Nanyang Technological University, Singapore 639798, Singapore

*Author for correspondence: assubbu@ntu.edu.sg
Future 
repeated dosing, and rapid washout by tear and lachrymal drainage systems. These factors limit the tissue bioavailability of this method of administration to less than $5 \%$. Although there are some reports of attempts to treat posterior segment diseases by topical delivery [4], this is, in general, not a viable route due to the presence of multiple tissue barriers to drug delivery, and huge wastage of the drug due to the low bioavailability of such treatment methods, in addition to the possibility of systemic side effects.

Systemic route of administration is used for treatment of certain conditions of the anterior and posterior segments, such as antibiotics, medications for severely raised intraocular pressure (IOP) or for pain relief. This route of administration, however, has limited success in treatment of posterior segment disorders due to the presence of blood-ocular barriers, particularly the blood-retinal barrier.

The intravitreal delivery method is the preferred route for posterior segment disorders due to the ability to deliver the therapeutic agents in close proximity to the target tissue. However, certain chronic conditions affecting the posterior segment (such as AMD and DME) require repeated intravitreal injections, and this may lead to several complications such as retinal detachment, cataract and endophthalmitis. The viscosity of the vitreous humor hinders diffusion of drugs and macromolecules, and leads to nonuniform diffusion kinetics and distribution profiles of drugs delivered intravitreally. Small molecules can distribute rapidly and in more quantity through the vitreous, compared with large molecules [5].

Periocular routes of drug delivery are gaining popularity in recent times as a noninvasive alternative to intravitreal delivery. In this, the drug molecules (with or without entrapment in carriers) are introduced in the subconjunctival, retrobulbar, posterior juxtascleral or subtenon spaces, without affecting the integrity of the eyeball, from where it reaches the target tissues (the retina or retinal pigment epithelium [RPE] usually) [6]. Of the periocular routes, the subconjunctival route is considered less invasive compared with subretinal, suprachoroidal or subtenon routes of delivery. Figure 1 shows a schematic presentation of the ocular structure with the various tissue and routes of drug administration and kinetics illustrated.

The drug administered by the periocular route may reach the posterior segment by any of three different pathways: trans-scleral diffusion, systemic circulation through the choroid or the anterior pathway through the tear film, cornea, aqueous humor and the vitreous humor. This method has its limitations too, as the drug washout is high and the drug needs to pass through static, dynamic and metabolic barriers to have therapeutic levels at the site of action [8]. This route can however, be made viable if the drugs are protected from washout and clearance. This can be achieved by entrapment of the therapeutic agent in carriers such as microparticles or nanoparticles, or polymer films or implants, to provide protection from degradation/ clearance as well as sustained delivery. The chronic nature of several ocular disorders also benefits from such a sustained delivery approach, which can help to deliver the therapeutic dose over a longer duration. The focus of this review will be on sustained delivery of nanomedicines to the posterior ocular segment; however, we briefly describe some research on sustained anterior segment delivery via the subconjunctival route, as this route is also potentially useful for posterior segment delivery.

\section{Sustained anterior segment drug delivery}

Most of the anterior segment diseases are treated via eye drops or topical administration [9], which have limited bioavailability and less duration of action, thus requiring frequent administration. Most of the sustainedrelease formulations focus on precorneal retention improvement. However, post-operative inflammation management (after cataract, glaucoma surgery etc.) in anterior segment disease management can greatly benefit from sustained delivery. Patient compliance is usually low in such cases, which can be a major impediment to effective treatment. Sustained-release forms of the drug can provide longer release of the drug, and for the required duration, and maintain the effectiveness of treatment without compromising on patient comfort and safety. Subconjunctival injection/implantation is a treatment of choice in such cases, as this route circumvents the immediate washout and precorneal drainage losses.

Much of the research in sustained delivery of topical formulations is aimed at improving the corneal residence time, typically from minutes to about $5-8 \mathrm{~h}$ [911] by the modification of formulation factors or by use of mucoadhesive materials. Also, contact lenses, soaked with drugs or loaded with drug containing nanoparticles, have also been used to effectively increase drug residence time compared with topical ophthalmic eye drops [12]. The reader is directed to detailed reviews by Zimmer \& Kreuter [13] and, more recently, by Almeida et al. [9], Cholkar et al. [11] and Molokhia et al. [14] on sustained-release mechanisms in anterior segment treatment. In this review, we will be focusing on the use of the subconjunctival route to provide sustained delivery to the anterior segment.

In a recent study, a liposomal formulation was developed for delivery of latanoprost to anterior segment ocular tissues, for glaucoma treatment by Nata- 


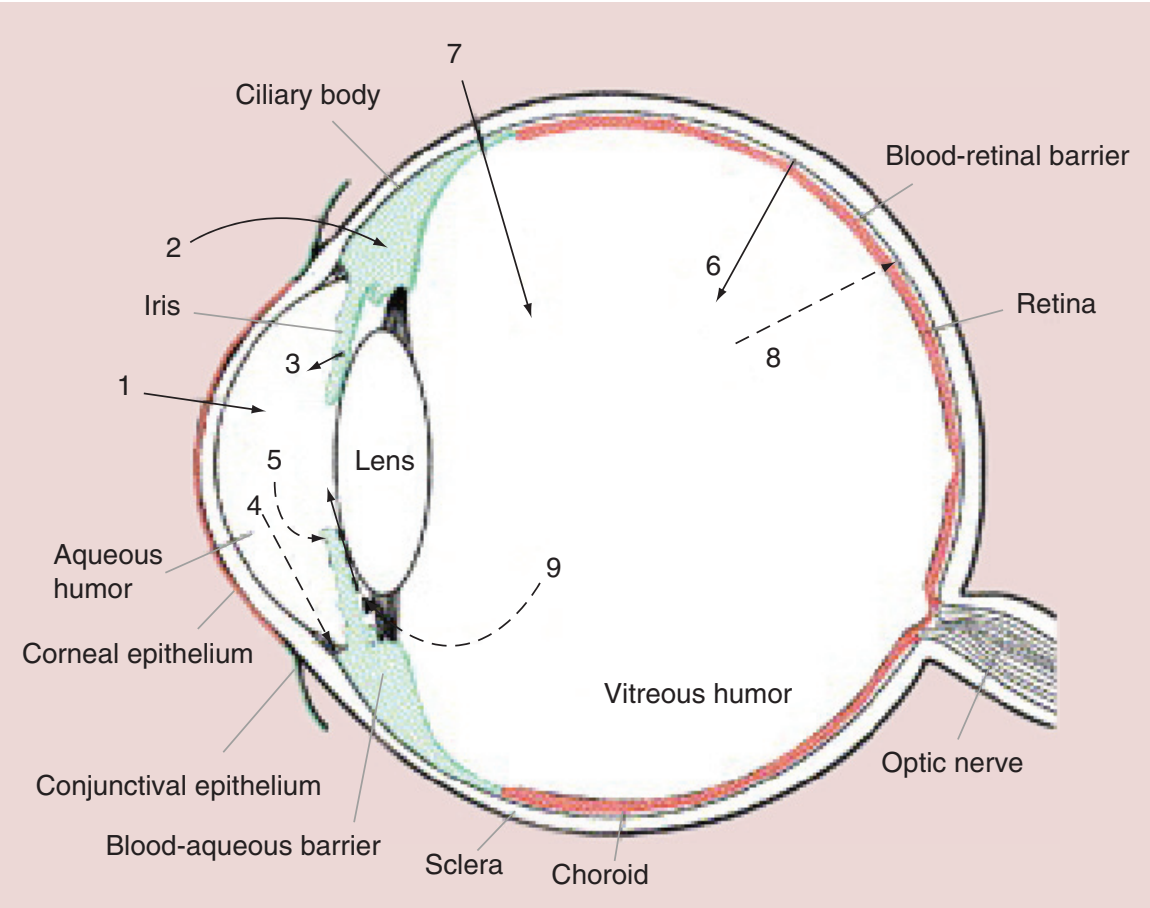

Figure 1. Schematic presentation of the ocular structure with the various tissue and routes of drug kinetics illustrated. The numbers refer to following processes: (1) transcorneal permeation from the lacrimal fluid into the anterior chamber, (2) noncorneal drug permeation across the conjunctiva and sclera into the anterior uvea, (3) drug distribution from the blood stream via blood-aqueous barrier into the anterior chamber, (4) elimination of drug from the anterior chamber by the aqueous humor turnover to the trabecular meshwork and Sclemm's canal, (5) drug elimination from the aqueous humor into the systemic circulation across the blood-aqueous barrier, (6) drug distribution from the blood into the posterior eye across the blood-retina barrier, (7) intravitreal drug administration, (8) drug elimination from the vitreous via posterior route across the blood-retina barrier and (9) drug elimination from the vitreous via anterior route to the posterior chamber.

Reproduced with permission from [7] @ Elsevier (2006).

rajan et al. [15]. A single subconjunctival injection of this liposomal formulation was able to demonstrate sustained IOP lowering effect in rabbit eyes over a period of 50 days with IOP reduction comparable to daily eye drop administration. This formulation has shown sustained IOP lowering for up to 120 days in nonhuman primates and beyond 3 months in a Firstin-Man clinical trial conducted in Singapore [16]. This product, marketed as Lipolat, is currently licensed to Peregrine Ophthalmic and is in Phase II clinical trials.

Subconjunctivally implanted films can potentially deliver drugs in a sustained fashion, especially for postoperative management. By placing the implant after surgery, the need for any additional insertion or removal procedure is eliminated. Implants made from biodegradable materials such as poly(lactide-cocaprolactone) (PLC) and poly(lactic-co-glycolic acid) (PLGA) can provide sustained delivery of anti-inflammatory agents postsurgery, which can improve patient compliance as well as boost the success rate of surgery.

Surodex ${ }^{\mathrm{TM}}$ (Allergan, Inc., CA, USA) is a commercial rod-shaped biodegradable PLGA-hydroxypropyl methylcellulose implant for delivering dexamethasone $(60 \mu \mathrm{g})$ which provides sustained drug release at a constant rate over 7-10 days. This implant is inserted into the anterior chamber after cataract surgery to control postoperative inflammation.

A polylactic acid (PLA) microsphere-accumulated disc containing 5 -fluorouracil demonstrated lower IOP for up to 90 days and longer persistence of filtration blebs after implantation at glaucoma filtration surgery site in a rabbit model [17].

A timolol-maleate-loaded biodegradable PLC microfilm was developed by $\mathrm{Ng}$ et al., and demonstrated to provide sustained delivery at therapeutic concentrations for up to 90 days in vitro, and IOP reduction in a primate model for up to 5 months with a single implant [18]. The authors were able to achieve longer duration of release and minimize the burst release in this case by the use of blended PLC-PEG films and a sandwich style three-layered film with the drug in the middle layer.

Prednisolone acetate (PA)-loaded PLC sandwich microfilms (with differential loading in the lay- 
ers) were studied by Ang et al. as a subconjunctival implant for treatment of recurrent uveitis [19]. The sandwich PA-loaded microfilm formulations exhibited higher release kinetic compared with homogeneous PA-loaded microfilms in vitro. The microfilm which had $60-40-60 \%$ in the trilayer released an average of $0.034 \mathrm{mg} /$ day of PA over the period of 60 days in vitro; and approximately $0.12 \mathrm{mg} / \mathrm{day}$ in vivo, in a rabbit model of experimental uveitis.

Biodegradable PLC films loaded with PA were also studied for efficacy in postoperative inflammation management after glaucoma filtration surgery [20]. PA-loaded microfilms with 20\% loading had steady, sustained-release in vitro. In animal studies, rabbit eyes implanted with PA-loaded microfilms had significantly higher bleb survival (100 vs $37.5 \%$ in controls) and reduced bleb vascularity compared with the control at 30 days. In addition to providing sustained release of PA for up to a month, the location of the implant next to the surgical bleb can provide more targeted and localized effect on the desired subconjunctival tissue.

\section{Sustained posterior segment drug delivery}

Management of several posterior segment disorders requires long-term treatment, and mostly with invasive methods, due to the limitations of systemic and topical methods in achieving the required drug levels in the vitreous or retina without causing significant adverse effects [21].

Maintaining long-term therapeutic concentrations within the vitreous or retina has been explored with the use of sustained-release mechanisms through the intravitreal as well as the periocular route. To this end, much research has been happening in the last few years in developing various sustained-release formulations, including gels, microparticles, nanoparticles and liposomes. Microparticles and nanoparticles introduced in the vitreous humor or periocular space can sustain the delivery of the encapsulated agents for longer durations compared with the drug alone [13,22-25]. Liposomes are also extensively studied for intravitreal and subconjunctival sustained delivery by many research groups [26-36]. For delivery of therapeutic agents for longer periods in a more controlled manner, solid implants or polymeric films have demonstrated the ability for sustained delivery of agents to the posterior ocular segment [19,37-44]. Another interesting sustained-release formulation is POT-4 (Potentia Pharmaceuticals, KY, USA), which is a synthetic peptide that reversibly binds complement factor C3 and functions as a complement inhibitor. When injected intravitreally at high doses, POT-4 forms an intravitreal gel by itself, forming a drug depot, which can then sustain therapeutic levels of the compound for several months following a single injection
(ClinicalTrials.gov identifier: NCT00473928) [45]. In the following section, we cover some of the promising sustained delivery mechanisms: particulate systems, liposomes and implants for prolonging the therapeutic effect of drugs via both the intravitreal as well as the subconjunctival routes.

\section{Particulate systems: microparticles and nanoparticles}

On the basis of their size, polymeric particulates can be classified as microparticles, which are particulate systems of sizes more than $1 \mu \mathrm{m}$, while nanoparticles are defined as particles with a diameter of less than $1 \mu \mathrm{m}$, which could consist of various natural or synthetic polymers, lipids and even inorganic materials. These can be broadly classified as nano/microspheres in which case the drug molecules may either be integrated in the matrix or nano/microcapsules wherein the drug is entrapped in a cavity enclosed by a polymeric shell.

Among the various polymers developed to formulate polymeric nanoparticles, PLGA has attracted considerable attention due to its biodegradability and biocompatibility, having secured US FDA approval for parenteral administration. Several PLGA-based nano/microparticle formulations have been studied for sustained delivery to the posterior segment of the eye.

Intravitreal administration of particulate systems Anti-VEGF aptamer EYE001 (which has been tested in humans for efficacy) entrapped in PLGA microspheres was found to deliver EYE001 in a sustained manner, with an average rate of $2 \mu \mathrm{g} /$ day over a period of 20 days, with retained activity in vitro and ex vivo [46]. Pan et al. studied the reduction in size of experimentally induced choroidal neovascularization (CNV) in rat eyes treated with bevacizumab, PEG-bevacizumab conjugate (b-PEG) and PLGA-encapsulated bevacizumab (b-PLGA), with varying time intervals between induction of CNV and intravitreal injection [47]. The authors found a significant decrease in CNV area compared with the saline control with all the formulations, but no significant difference between the subgroups consisting of free bevacizumab, PEGylated bevacizumab and b-PLGA.

Li et al. studied the entrapment of bevacizumab in PLGA nanospheres, of size range $0.2-1 \mu \mathrm{m}$, compared with that of two PEG- $b$-PLA microsphere formulations with varying ratio of PEG, for entrapment and drug release from these different polymers [48]. The ratio of PEG influenced the hydrophilicity of the polymer and thus the entrapment ratio. Compared with PLGA, the hydrophilic polymer facilitated better dispensing into the matrix, but the higher hydrophilic PEG content polymer resulted in a lower yield 
of the particles as the majority of the polymer was dissolved in the water phase during particle preparation. The PLGA nanospheres exhibited sustained release for up to 90 days in vitro. Albuminated PLGA nanoparticles of bevacizumab, injected intravitreally in rabbits, were found to maintain the vitreous concentration of bevacizumab above $500 \mathrm{ng} / \mathrm{ml}$ for about 8 weeks, and retain the activity, protected against aggregation and instability (as measured by ELISA) [49].

PLA microparticles, with an average diameter of $7.6 \mu \mathrm{m}$, encapsulating TG-0054 (a hydrophilic drug intended for neovascularization-related diseases), were found to have sustained release for up to 3 months in a rabbit model. Drug levels in the microparticle-dosed eyes at 3 months were $43.7 \pm 16.2,243 \pm 42.6$ and 62.8 $\pm 22.6 \mu \mathrm{g} / \mathrm{g}$ in the vitreous, retina and choroid-RPE, respectively, and similar to levels at 1 month. At the same time, intravitreal injection of plain drug solution resulted in low intraocular levels at 1 month, with no detectable drug at 3 months [50].

Zhang et al. explored dexamethasone-loaded PLGA nanoparticles (average size: $232 \mathrm{~nm}$ ) injected intravitreally in rabbits and found the particles exhibiting sustained release up to 50 days in the vitreous, with a relatively constant mean concentration of $3.85 \mathrm{mg} / \mathrm{l}$ over 30 days, compared with a solution of dexamethasone which was not detectable 7 days after injection [51].

PLGA microspheres loaded with triamcinolone acetonide (TA) microspheres were tested in human patients suffering from diffuse macular edema [52]. Eyes treated with intravitreal injection of triamcinolone-loaded microspheres (referred to as the RETAAC system by authors) showed marked decrease of retinal thickness as well as improved visual acuity for 12 months.

The ocular disposition of ganciclovir-loaded albumin nanoparticles, introduced via intravitreal injection, was studied by Merodio et al., and the particles were detectable in the vitreous for up to 2 weeks postinjection [53]. No adverse effects or inflammatory reactions were observed histologically in the retina or adjacent ocular tissues.

Although intravitreously administered particulate systems sustain vitreous drug levels, the suspended particles in the vitreous increase polymeric burden in the eye and are likely to interfere with vision. Intravitreal distribution of nanoparticles is found to be dependent on the size, charge and surface properties of the particles [53-60]

Periocular administration of particulate systems Microparticles or nanoparticles may be introduced in the periocular space, from where the encapsulated cargo might be transported across the ocular tissues, to reach the required site. Below, we describe some significant studies on sustained delivery of drugs by nano/microparticles via the periocular route of administration.

Subconjunctival PLA microparticles of $3.6 \mu \mathrm{m}$ and nanoparticles of $345 \mathrm{~nm}$ encapsulating budesonide [22] were found to demonstrate sustained release for up to 2 weeks from microparticles, and for 1 week from nanoparticles in Sprague-Dawley (SD) rats. Budesonide PLA nanoparticles and microparticles had encapsulation efficiencies of 65 and 99\%, respectively. For the nanoparticles, the retinal, vitreous and corneal budesonide concentrations were significantly higher than in the solution group, whereas for microparticles, the budesonide concentration was higher than nanoparticle and solution group on day 14 . The nanoparticles also showed a higher burst and lower encapsulation compared with microparticles.

TA-loaded PLA nanoparticles $(551 \mathrm{~nm})$ and microparticles $(2090 \mathrm{~nm})$, with 14.7 and $29.5 \%$ drug loading, respectively, were compared for subconjunctival delivery in experimentally induced CNV, in a rat model. The nanoparticles and microparticles sustained TA release for about 45 and 120 days, respectively, in vitro. In vivo, microparticles were able to sustain the delivery in all intraocular tissues for 2 months after subconjunctival injection, whereas no ocular drug levels were detected for TA-loaded nanoparticles and plain suspension of TA. A significant amount of microparticles remained in periocular tissue at 2 months after injection, and maintained their spherical shape. The authors conclude that microparticles, not nanoparticles, were able to better sustain the delivery by the subconjunctival route [61].

Celecoxib-PLGA (85:15) microparticles with mean diameters of $3.9 \mu \mathrm{m}$ size and $68.5 \%$ loading efficiency were seen to sustain delivery to the retina for up to 14 days in treatment of diabetes-induced retinal abnormalities in a rat model [24]. In vitro, the microparticles sustained celecoxib release for 49 days. Subconjunctivally administered celecoxib-PLGA microparticles sustained retinal and other ocular tissue drug levels during the 14-day study in rats.

Dendrimeric nanoparticles, encapsulating carboplatin, were found to have sustained effect in treatment of murine retinoblastoma, when injected subconjunctivally [62]. The size of dendrimers being about $258 \mathrm{~nm}$, the particles by themselves are not expected to have moved through the sclera, but only the entrapped drug, or the decomposed dendrimer fragments. Traces of the drug were detected in the contralateral eye in this case, which indicates that the drug had been cleared by systemic circulation, postadministration. 


\section{Liposomes}

Liposomes are vesicular systems, composed of an aqueous core, and surrounded by a lipid bilayer. Based on the drug properties (hydrophobic or hydrophilic), entrapment of the drug might be achieved either in the core (for hydrophilic drugs) or in the bilayer (for hydrophobic drugs). Properties of liposomes such as size, charge and lipid composition can be easily manipulated, which makes them versatile as nanocarriers for ocular drug delivery. Moreover, they exhibit favorable properties such as low toxicity, biodegradability and the potential to encapsulate a variety of drugs with different properties. Liposomes have been extensively studied for these reasons for encapsulation of ocular therapeutics.

Intravitreal administration of liposomes

Verteporfin, a hydrophobic photosensitizer, has been shown to be highly effective for photodynamic therapy for treatment of CNV, but it undergoes self-aggregation in aqueous media, which can severely limit drug bioavailability to biological systems. Therefore, verteporfin in liposomes (Visudyne) is used for intravenous drug delivery, followed by photodynamic therapy. The mechanism of action of this therapy involves preferential uptake of this photosensitizing dye, which when activated by specific laser light energy, selectively closes the CNV vessels by thrombosis. To date, Visudyne (verteporfin in liposomes) has been the only ocular liposomal drug approved by FDA [63].

Abrishami et al. prepared nanoliposomes of bevacizumab for intravitreal injection in rabbits. Compared with free drug, the vitreal concentration of bevacizumab from the liposomal formulation was five-times higher at 42 days [27]. This study shows that intravitreal liposomal formulations are capable of sustaining delivery of anti-VEGF agents for at least 6 weeks. However, retention of antibody activity is a major concern, while encapsulating protein drugs or antibodies.

Liposomal ganciclovir, injected intravitreally, was found to have sustained intravitreal drug concentrations above the inhibitory concentration for cytomegalovirus $(1 \mu \mathrm{g} / \mathrm{ml})$, for up to 43 days, in rabbits [64]. The plain drug solution, on the other hand, exhibited the concentration above the $\mathrm{ID}_{50}$ only for $55 \mathrm{~h}$.

Tacrolimus-loaded liposomes were utilized for the treatment of uveoretinitis in a rat model by Zhang et al. Intravitreally injected liposomes were able to maintain the vitreous concentration at more than $50 \mathrm{ng} / \mathrm{ml}$ for 2 weeks after a single injection, compared with the drug alone [65].

\section{Periocular administration of liposomes}

Subconjunctival injection of drug containing liposomes may result in some drug transport to the back of the eye. Patient compliance and comfort are also higher in subconjunctival administration compared with intravitreal route. However, there have not been many studies on periocular administration of liposomes targeting posterior segment disorders.

Subconjunctival injection of liposome-bound lowmolecular-weight heparin (LMWH) was tested in rabbits for the treatment of subconjunctival hemorrhage. Compared with free LMWH, the concentration of liposome-bound LMWH was lower in the ocular tissues, and in the systemic circulation. LMWH by itself has a narrow therapeutic range, and there is the potential risk of systemic and ocular side effects with high doses. When encapsulated in liposomes, the sustained and slowed delivery is able to overcome this toxicity issue as well. The liposomes were expected to remain at the site of injection and not be cleared away by lymphatic drainage, considering that they had a size of approximately $550 \mathrm{~nm}$. Positively charged liposomes encapsulated higher amounts of LMWH and released the drug in a sustained manner, providing longer residence time and increased concentration at the target site [66].

\section{Composite systems}

Several 'Russian-doll'-like composite systems, incorporating particles inside other particles, or particles in gels, have been explored for extending the release duration, or for overcoming limitations of single-carrier systems.

Yandrapu et al. prepared PLA nanoparticles (size: $251 \pm 15 \mathrm{~nm}$ ) in porous PLGA microparticles (final size: $11.6 \mu \mathrm{m}$ ) with bevacizumab, using supercritical carbon dioxide technology. These composite particles showed a sustained release of bevacizumab for 4 months in vitro. Bevacizumab was detectable for up to 2 months in a rat model with intravitreal administration of the composite particles, compared with only 2 weeks for the administration of bevacizumab solution alone [67].

PLGA microparticles, entrapping chitosan nanoparticles, in a composite system to entrap ranibizumab were developed by Elsaid et al. [68]. The in vitro release from this system was quantifiable for up to 120 days. The blank PLGA microparticles had a ranibizumab encapsulation efficiency of $29 \pm 3.8 \%$, while the addition of chitosan nanoparticles caused a decrease in overall ranibizumab entrapment efficiency $(13 \pm$ $2.0 \%)$.

A composite drug delivery system consisting of ranibizumab or aflibercept, in PLGA microparticles, suspended in a thermoresponsive, injectable, poly $(\mathrm{N}$ isopropylacrylamide) (PNIPAAm) hydrogel was developed by Osswald \& Kang-Mieler [69]. This gel can 
release either ranibizumab or aflibercept for 196 days with an initial burst of $22.2 \pm 2.2$ and $13.1 \pm 0.5 \mu \mathrm{g}$, respectively, followed by controlled release of 0.153 and $0.065 \mu \mathrm{g} /$ day, respectively.

Hirani et al. studied a composite system consisting of TA nanoparticles encased in a PLGA-PEG-PLGA thermoreversible gel. The PEGylated-PLGA nanoparticles had a mean size of $208 \mathrm{~nm}$ with a uniform size distribution. The composite system was also found to significantly reduce VEGF expression in the human RPE cell-line (ARPE-19 cell line) by $43.5 \pm 3.9 \%$, as compared with a $1.53 \pm 11.1 \%$ reduction with plain triamcinolone [70].

\section{Hydrogels}

Hydrogels are 3D, crosslinked polymeric networks capable of absorbing large quantities of water. Their diffusion and permeability properties can be easily tuned by varying processing parameters such as crosslinking time, temperature, type of crosslinker, ratio of polymer and crosslinker, thus varying the crosslinking density. Compared with hydrophobic polymers such as PLA or PLGA, hydrogels are usually formed at ambient temperatures, without the need for organic solvents or harsh processing conditions, which may denature proteins or antibodies. This, combined with the presence of an aqueous internal environment, makes hydrogels attractive candidates for entrapment of fragile entities such as proteins, antibodies, peptides, cells, and oligonucleotides. In ocular drug delivery, hydrogels have been explored for sustained delivery of drugs, intravitreally as well as periocularly [71].

Hyaluronic acid (HA)/dextran-based in situ hydrogel were loaded with bevacizumab for intravitreal injection in rabbit eye by $\mathrm{Yu}$ et al. The release of bevacizumab was found sustained for up to 6 months after a single intravitreal injection, and the retinal structure was not affected by implantation of the in situ gel [72]. This study shows the significant potential of hydrogels in sustained delivery of anti-VEGF.

A biodegradable, thermally responsive hydrogel, based on poly(ethylene glycol)-poly(serinol hexamethylene urethane) (ESHU), was developed to deliver bevacizumab in rabbit eyes. In vivo, the ESHU gel did not elicit significant inflammatory response, and the release of bevacizumab was sustained for over 9 weeks, with preserved bioactivity (as determined by ELISA) [73].

Intravitreal injection of a gel formulation of hydrophilic-hydrophobic block copolymers of methoxypoly(ethylene glycol)-block-poly(lactic-co-glycolic acid) (mPEG-PLGA), crosslinked with 2,2-bis (2-oxazoline), was found to sustain bevacizumab for up to a month in vivo in a rabbit study. The mPEG-PLGA- 2,2-bis(2-oxazoline) hydrogel had no cytotoxicity in vivo, as demonstrated by retinal histological analysis. The released bevacizumab inhibited the choroid-retina endothelial $(\mathrm{RF} / 6 \mathrm{~A})$ and human umbilical vein endothelial (HUVEC) cell proliferation, indicating that the bioactivity was preserved after release [74].

Wang et al. developed a biodegradable and thermosensitive triblock copolymer consisting of poly(2ethyl-2-oxazoline)-b-poly( $\varepsilon$-caprolactone)-b-poly(2ethyl-2-oxazoline) that can sustain the release of bevacizumab in vitro. The gel demonstrated good biocompatibility, as evidenced by preserved electrophysiology of the rabbit retina 2 months after intravitreal injection. Although in vivo drug release results are not reported by the authors, the results show potential for sustained in vivo release for bevacizumab using this novel gel system [75].

Lovett et al. have developed silk hydrogels, incorporating anti-VEGF drugs such as bevacizumab [76]. These hydrogel formulations demonstrated sustained release of 3 months or greater both in vitro and in vivo, after intravitreal injection in Dutch-belted rabbits. Vitreous concentrations at 3 months postadministration were equivalent or greater than the levels for positive control at 1 month. The bioactivity of bevacizumab on release from the hydrogel was preserved, as observed by ELISA measurement. Terminal fundus photographs and ophthalmic examinations indicated no major signs of ocular tissue abnormalities, and at 3 months, biodegradation of the hydrogel was observed. Unlike PLGA-based hydrogels, which generate acidic degradation by products that may affect the drug bioactivity, silk hydrogels offer an alternative for maintaining bioactivity of protein therapeutics, for sustained delivery.

Tyagi et al. developed a light-activated in situ gelling system for bevacizumab, which was introduced in the suprachoroidal space [77]. The in vivo drug measurement was done noninvasively with the Flurotron Master $^{\mathrm{TM}}$ instrument, using Alexa Fluor ${ }^{\circledR} 488$-tagged bevacizumab: detectable levels of bevacizumab were observed for at least 60 days in the suprachoroidal space of SD rats. In vitro, the polycaprolactone dimethacrylate (PCM) and hydroxyethyl methacrylate (HEMA) gel sustained bevacizumab release for 4 months, and was found to maintain the stability and VEGF-binding activity.

Subconjunctivally delivered topotecan in a fibrin sealant [78] was tested for treatment of murine retinoblastoma. A subconjunctival depot so formed was able to sustain the delivery for up to 3 weeks postadministration.

Delivery of cisplatin from a subconjunctivally injected collagen matrix was studied by Gilbert et al. [79]. Subconjunctival injection of cisplatin in 
the collagen matrix vehicle in a rabbit model achieved mean concentrations of $3.3 \mu \mathrm{g} / \mathrm{ml}$ in the vitreous humor at $1.5 \mathrm{~h}$ and $0.1 \mu \mathrm{g} / \mathrm{ml}$ at 2 weeks. Choroidal and retinal cisplatin concentrations of $73.5 \mu \mathrm{g} / \mathrm{mg}$ at $1.5 \mathrm{~h}$ and $3.2 \mu \mathrm{g} / \mathrm{mg}$, respectively, were observed at 2 weeks. Compared with a control infusion of saline, the concentrations were sustained after subconjunctival injection using this collagen matrix.

Misra et al. developed a biodegradable thermoresponsive hydrogel based on NIPAAm for delivery of insulin. The hydrogels were implanted subconjunctivally and had a loading efficiency of up to $98 \%$. The hydrogels were able to release biologically active insulin in vitro for at least 1 week. In vivo release results were not reported; however, electroretinography studies indicate that the hydrogels implanted subconjunctivally in SD rats do not induce retinal damage or inflammatory reactions after 7 days [80].

A biodegradable and thermosensitive triblock copolymer consisting of PLGA and PEG was studied by Rieke et al., to deliver a surrogate large protein ovalbumin $\left(\mathrm{M}_{\mathrm{w}}: 45 \mathrm{kDa}\right)$, postsubconjunctival administration, in Norway rats. Ovalbumin concentrations were found to be maintained at measurable levels in the sclera, choroid and retina of rats for up to 14 days using the gel, indicating its potential use for delivery of anti-VEGF molecules which are large proteins [81].

\section{Intraocular implants (biodegradable/} nonbiodegradable)

Intravitreal implants are intended to provide long-term sustained delivery, which can outlast both solution and particulate formulations. The nonbiodegradable implants can provide stable and controlled delivery of the therapeutic agents in close proximity to the required tissue, and minimizing toxicity and adverse side effects. However, the implantation procedure itself is invasive, and once the drug is depleted, the device needs to be taken out by another procedure. In light of these, several biodegradable implants have also been developed for sustained delivery. Biodegradable implants, however, do not require surgical removal, but often exhibit a final uncontrolled burst release, from the degradation. Implants provide a more consistent level of drug release, but they carry a risk of infection following insertion or removal.

There are currently two FDA-approved sustainedrelease corticosteroid implants: Retisert (Bausch \& Lomb, NY, USA) and Ozurdex (Allergan Inc., CA, USA). Ozurdex is a biodegradable dexamethasone intravitreal implant made of PLGA [66], which delivers sustained concentrations of dexamethasone in the vitreous, for up to 6 months. This implant is indicated for treatment of DME. Retisert is a nonbiodegradable implant for Fluocinolone Acetonide (FA; $0.59 \mathrm{mg} /$ insert) for treatment of noninfectious chronic uveitis, affecting the posterior segment, which can sustain the delivery of the drug up to 3 years [39]. However, it is associated with side effects such as increase in IOP and high incidence of cataract formation.

Iluvien is a nonbiodegradable, rod-shaped implant for FA ( $0.19 \mathrm{mg} /$ insert $)$ which can release the drug over 3 years [40] and for indications of DME. Iluvien insertion is an in-office procedure. Vitrasert is a nonbiodegradable implant of ganciclovir, consisting of polyvinyl alcohol (PVA) and ethylene vinyl acetate (EVA) membranes coated on a pellet, targeted for cytomegalovirus retinitis, able to sustain delivery for 5-8 months [82]. I-vation (Surmodics, Inc. MN, USA) is a nonbiodegradable, helical-shaped sustained-release implant containing $0.925 \mu \mathrm{g}$ TA, designed for uveitis treatment. The implant, coated in titanium, PVA and EVA can be anchored to the sclera via a small pars plana incision. The implant can last up to 2 years.

\section{Intrascleral depots}

Okabe et al. have demonstrated sustained delivery of betamethasone, using an intrascleral nonbiodegradable depot device, consisting of a copolymer of EVA [44] in a rabbit model, which was capable of delivering the drug for up to a month, to the posterior segment. The betamethasone concentrations in the retina-choroid around the implantation site were more than ten-times higher than in the contralateral side, pointing to a nonsystemic route of drug diffusion from the intrascleral implant. The drug levels in the retina-choroid, after the placement of the intrascleral implants, remained higher than effective concentrations for suppression of inflammation, for at least 28 days.

In another study, from the same group, using biodegradable PLA intrascleral implants for the delivery of betamethasone phosphate [43], in vitro release was sustained over 50 days, and in vivo, more than $80 \%$ of drug was released at 28 days. The concentration of the drug in retina-choroid was maintained at an effective level for suppressing inflammation for more than 8 weeks, and histologically no adverse effects were observed.

Biodegradable scleral plugs with PLGA, encapsulating FK506 (tacrolimus) was found to have sustained intravitreal levels for up to 6 weeks postintroduction, in a rabbit model [38].

Novel strategies \& devices for sustained release to the posterior segment

Periocular delivery with solid or hollow microneedles has a potential for sustained delivery, with the delivery of nanoparticles or microparticles into the sclera 
Table 1. Summary of different sustained delivery systems for posterior segment.

\begin{tabular}{|c|c|c|c|c|}
\hline Delivery system & Drug & $\begin{array}{l}\text { Type of } \\
\text { administration }\end{array}$ & Significant advantage demonstrated & Ref. \\
\hline PLA microparticles & $\begin{array}{l}\text { TG-0054 (a hydrophilic } \\
\text { drug intended for } \\
\text { neovascular diseases) }\end{array}$ & $\begin{array}{l}\text { Intravitreal injection } \\
\text { in New Zealand white } \\
\text { rabbits }\end{array}$ & $\begin{array}{l}\text { Significant vitreous, retinal and choroidal } \\
\text { concentrations of drug found at } 3 \text { months, } \\
\text { compared with plain drug }\end{array}$ & [50] \\
\hline PLGA microparticles & $\begin{array}{l}\text { Anti-VEGF aptamer } \\
\text { EYE001 }\end{array}$ & $\begin{array}{l}\text { Only in vitro study } \\
\text { reported }\end{array}$ & $\begin{array}{l}\text { Sustained release for over } 20 \text { days, with } \\
\text { retention of activity }\end{array}$ & [46] \\
\hline PLGA microparticles & $\begin{array}{l}\text { Triamcinolone } \\
\text { acetonide }\end{array}$ & $\begin{array}{l}\text { Intravitreal injection; } \\
\text { human subjects }\end{array}$ & $\begin{array}{l}\text { Marked decrease of retinal thickness } \\
\text { as well as improved visual acuity for } \\
12 \text { months }\end{array}$ & [52] \\
\hline $\begin{array}{l}\text { Albuminated PLGA } \\
\text { nanoparticles }\end{array}$ & Bevacizumab & Intravitreal & $\begin{array}{l}\text { Sustained release with antibody protection } \\
\text { from aggregation and instability }\end{array}$ & [49] \\
\hline $\begin{array}{l}\text { PLA microparticles and } \\
\text { nanoparticles }\end{array}$ & $\begin{array}{l}\text { Triamcinolone } \\
\text { acetonide }\end{array}$ & Periocular injection & $\begin{array}{l}\text { Triamcinolone acetonide microparticles } \\
\text { sustained delivery for up to } 2 \text { months } \\
\text { postinjection, compared with nanoparticles } \\
\text { and controls }\end{array}$ & [61] \\
\hline $\begin{array}{l}\text { PLGA (85:15) } \\
\text { microparticles }\end{array}$ & Celecoxib & $\begin{array}{l}\text { Subconjunctival } \\
\text { injection }\end{array}$ & $\begin{array}{l}\text { Sustained retinal delivery for up to } 14 \text { days } \\
\text { in treatment of diabetes-induced retinal } \\
\text { abnormalities in rats }\end{array}$ & [24] \\
\hline $\begin{array}{l}\text { Dendrimeric } \\
\text { nanoparticles }\end{array}$ & Carboplatin & Subconjunctival & $\begin{array}{l}\text { Treatment of transgenic murine } \\
\text { retinoblastoma, with no associated toxic } \\
\text { effects }\end{array}$ & [62] \\
\hline $\begin{array}{l}\text { Nanoparticles in } \\
\text { thermosensitive gels }\end{array}$ & $\begin{array}{l}\text { Triamcinolone } \\
\text { acetonide }\end{array}$ & $\begin{array}{l}\text { Only in vitro study } \\
\text { reported }\end{array}$ & Sustained release over 10 days & [70] \\
\hline $\begin{array}{l}\text { Hyaluronic acid/dextran- } \\
\text { based in situ hydrogel }\end{array}$ & Bevacizumab & Intravitreal & Sustained release up to 6 months in rabbits & [72] \\
\hline ESHU gel & Bevacizumab & Intravitreal & $\begin{array}{l}\text { Release of bevacizumab was sustained for } \\
\text { over } 9 \text { weeks in rabbits }\end{array}$ & [73] \\
\hline mPEG-PLGA gel & Bevacizumab & Intravitreal & $\begin{array}{l}\text { Bevacizumab release sustained for up to a } \\
\text { month in rabbits }\end{array}$ & [74] \\
\hline PEOz-PCL-PEOz gel & Bevacizumab & In vitro & In vitro sustained release up to 20 days & [75] \\
\hline Silk hydrogels & Bevacizumab & Intravitreal & $\begin{array}{l}\text { Sustained release up to } 3 \text { months in vitro as } \\
\text { well as in vivo in Dutch-belted rabbits }\end{array}$ & [76] \\
\hline $\begin{array}{l}\text { PCM-HEMA-based in situ } \\
\text { gel }\end{array}$ & Bevacizumab & Suprachroidal & 60 days in vivo retention in SD rats & [77] \\
\hline
\end{tabular}


Table 1. Summary of different sustained delivery systems for posterior segment (cont.).

\begin{tabular}{|c|c|c|c|c|}
\hline Delivery system & Drug & $\begin{array}{l}\text { Type of } \\
\text { administration }\end{array}$ & Significant advantage demonstrated & Ref. \\
\hline Fibrin sealant & Topotecan & Subconjunctival & $\begin{array}{l}\text { Sustained effect by depot action for up to } \\
3 \text { weeks postadministration }\end{array}$ & [78] \\
\hline Collagen matrix & Cisplatin & Subconjunctival & $\begin{array}{l}\text { Sustained delivery of cisplatin with the } \\
\text { collagen matrix vehicle compared with BSS, } \\
\text { for } 2 \text { weeks, in rabbits }\end{array}$ & [79] \\
\hline NIPAAm hydrogel & Insulin & $\begin{array}{l}\text { Only in vitro study } \\
\text { reported }\end{array}$ & Bioactive insulin released for up to a month & [80] \\
\hline PLGA-PEG hydrogel & $\begin{array}{l}\text { Ovalbumin (model } \\
\text { protein) }\end{array}$ & Subconjunctival & $\begin{array}{l}\text { Measurable protein concentrations in } \\
\text { various ocular tissues for up to } 14 \text { days }\end{array}$ & {$[81]$} \\
\hline Liposome & Ganciclovir & Intravitreal injection & Sustained release for up to 43 days & [64] \\
\hline Liposome & Bevacizumab & Intravitreal injection & Sustained release up to 42 days & [27] \\
\hline $\begin{array}{l}\text { Retisert } \\
\text { (nonbiodegradable } \\
\text { implant, PVA implant) }\end{array}$ & Fluocinolone acetonide & Intravitreal implant & $\begin{array}{l}\text { Chronic, noninfectious, posterior uveitis, } \\
\text { release up to } 3 \text { years }\end{array}$ & [39] \\
\hline $\begin{array}{l}\text { Iluvien (intravitreal } \\
\text { implant) }\end{array}$ & Fluocinolone acetonide & Intravitreal implant & $\begin{array}{l}\text { Chronic DME, release up to } 3 \text { years (slightly } \\
\text { lower daily dose compared with retisert) }\end{array}$ & {$[40]$} \\
\hline $\begin{array}{l}\text { Ozurdex (biodegradable } \\
\text { implant with PLGA) }\end{array}$ & Dexamethasone & $\begin{array}{l}\text { Rod-shaped } \\
\text { intravitreal implant }\end{array}$ & $\begin{array}{l}\text { First intravitreal implant corticosteroid } \\
\text { indicated for the treatment of DME for in } \\
\text { vivo delivery up to } 6 \text { months }\end{array}$ & [89] \\
\hline I-vation & $\begin{array}{l}\text { Triamcinolone } \\
\text { acetonide }\end{array}$ & Intravitreal implant & $\begin{array}{l}\text { Self-anchoring in the sclera, delivery of } \\
\text { triamcinolone acetonide over } 2 \text { years }\end{array}$ & \\
\hline $\begin{array}{l}\text { Nonbiodegradable } \\
\text { device, EVA copolymer }\end{array}$ & Betamethasone & Intrascleral & Sustained delivery of up to a month & {$[44]$} \\
\hline $\begin{array}{l}\text { Biodegradable, PLA } \\
\text { intrascleral implant }\end{array}$ & $\begin{array}{l}\text { Betamethasone } \\
\text { phosphate }\end{array}$ & Intrascleral & Sustained delivery of up to 8 weeks & {$[43]$} \\
\hline $\begin{array}{l}\text { PLGA biodegradable } \\
\text { scleral plug }\end{array}$ & FK506 (tacrolimus) & Intravitreal & $\begin{array}{l}\text { Intravitreal levels maintained for at least } \\
6 \text { weeks (for uveitis treatment) }\end{array}$ & {$[38]$} \\
\hline
\end{tabular}

or suprachoroidally [83-85]. Clearside Biomedical, Inc. (GA, USA) has developed microneedle-based technologies for treatment of macular edema, retinal vein occlusion, DME and AMD, which are currently undergoing clinical trials. (www.clinicaltrials. gov identifiers: NCT02303184, NCT02255032 and NCT01789320) [83-85].

Neurotech's (RI, USA) patented core technology, encapsulated cell technology, uses live cells to secrete a therapeutic agent. A specific type of cell is genetically engineered to overexpress a particular agent, and the cells are then encapsulated in polymeric capsules, which are later implanted at target sites. These can provide long-term sustained and controlled release of the therapeutic agents from the capsule. Also, the bioactivity of the agent is not compromised, as the proteins are synthesized in situ. Neurotech's NT-501 encapsulated cell technology consists of encapsulated cells that secrete recombinant human CNTF. A Phase II clinical study on NT-501 is ongoing, for treatment of retinal degenerative disorders [86].

Refillable implants are a novel class of devices developed for sustained release, for the posterior segment. Replenish, Inc. (CA, USA) has developed the MicroPump, a refillable implant that dispenses nanoliter-sized doses, as required. The device consists of a refillable drug reservoir, a flexible cannula and a check valve with a 31-gauge needle used to refill the reservoir. The device is thought to be capable of delivering therapeutics for AMD and other retinal degenerative disorders. Another biocompatible injectable implant, ODTx, has been developed by On Demand Therapeutics (CA, USA), which consists of multiple, sealed reservoirs to store and protect protein or macromolecular drugs until their desired release. The device, which is injected into the vitreous, in the region of pars plana, can be activated by laser which can be used to selectively open individual drug reservoirs, thus releasing 
the drug into vitreous $[87,88]$. Port delivery system (ForSight VISION4, Inc., MenloPark, CA, USA) is a refillable drug delivery device that is in Phases I and II trials for preliminary safety and efficacy for neovascular AMD and noninfectious uveitis (www.clinicaltrials. gov identifier: NCT02510794).

The various sustained-release formulations discussed for posterior segment are summarized in Table 1.

\section{Carrier properties determining distribution $\&$ fate of therapeutics in the posterior ocular segment}

In the previous section, we have summarized some of the carrier systems that have been explored for sustained delivery for posterior segment disorders. The distribution of carriers, after intravitreal and periocular administration, depends on the carrier properties and interaction with the ocular tissues. There have been many detailed studies on the effect of carrier properties on the action of carriers after intravitreal injection, but not many studies with regard to subconjunctival administration.

The anterior chamber, vitreous cavity and subretinal space of the eye are known to display immune privilege; however, synthetic biomaterials may still cause inflammatory reactions that can lead to detrimental effects on the eye. Therefore, characterization and toxicity studies on new and potential ocular biomaterials is imperative. Biodegradable particles may also present toxicity concerns, as the degradation products might be toxic.

In the anterior segment, the use of large-sized particles in topical formulations, particularly above $10 \mu \mathrm{m}$, is associated with a feeling of grittiness in the eye [13]. Positively charged liposomal formulations for corneal treatments are also found to cause an increase in rabbit blinking rate and irritation as evidenced by Draize tests. De Campos et al. examined the in vivo toxicity and fate of chitosan-based nanoparticles used for treatment of ocular surface diseases. It was found that for concentrations as high as $2 \mathrm{mg} / \mathrm{ml}$, there was no toxicity found in human conjunctival cell lines. The authors also hypothesize that the particles exhibit higher interaction with the conjunctiva versus the cornea, and that the nanoparticles are able to penetrate both corneal and conjunctival epithelia [90].

\section{Carrier properties determining intravitreal fate of carriers}

The vitreous humor is composed of $98-99 \%$ water weight/volume (w/v), and the solid component is mainly collagen fibrils and glycosaminoglycans, forming a viscous gel, which gives shape and form to the eyeball $[5,91]$. On introducing drug molecules, micro/ nanoparticles or implants to the vitreous humor, by the intravitreal route, there is slow diffusion of therapeutic agents to the posterior ocular tissues, followed by clearance (which might occur via the anterior route or via retinal vasculature), which depends on the size, charge and properties of the molecules [25,59,92-93].

Sakurai et al. [59] have studied the effect of size on intravitreal distribution of polymeric nanospheres (fluorescent polystyrene) of sizes $2 \mu \mathrm{m}$, and 200 and $50 \mathrm{~nm}$. The smaller $200-\mathrm{nm}$ nanoparticles were observed in the retina 2 months postinjection, while the micrometer-sized particles were found distributed in the trabecular meshwork and vitreous cavity. Considerable vitreous opacity was observed in the retina for particles of $2 \mu \mathrm{m}$ diameter, while the 200 or $50 \mathrm{~nm}$ particles were found distributed uniformly in the vitreous, 1 month postinjection. The micrometer-sized particles were probably too big to enter the retina. The $2-\mu \mathrm{m}, 200-\mathrm{nm}$ and 50-nm particles showed different half-lives, $5.4 \pm 0.8,8.6 \pm 0.7$ and $10.1 \pm 1.8$ days, respectively.

The effect of nanoparticle charge on intravitreal movement was investigated by Kim et al. by using cationic and anionic human serum albumin (HSA) nanoparticles [58]. Anionic nanoparticles of size $114 \mathrm{~nm}$ and an overall $\zeta$-potential of $-33.3 \mathrm{mV}$ were found to easily diffuse through the vitreal collagen fibrils and reach the retina, $5 \mathrm{~h}$ postinjection, while the cationic nanoparticles, which had an average diameter of $175.5 \mathrm{~nm}$ and a mean $\zeta$-potential of $+11.7 \mathrm{mV}$, were found to remain aggregated in the vitreous. The authors also examined the effect of disease condition on the migration, and observed that in the laser photocoagulated retina, more HSA nanoparticles were detected in the choroidal space, compared with the normal retina.

Intravitreal fate of several nanoparticles of similar size, but different surface properties, was examined by Koo et al. [57]. Similar to a previous observation with cationic HSA nanoparticles [58], it was seen that 316-nm-sized, positively charged polyethyleneimine (PEI) nanoparticles were stuck in the vitreous humor, at the site of injection, at 24 and $72 \mathrm{~h}$ time points postinjection. Another nanoparticle studied, glycol chitosan (GC) nanoparticle, which was also cationic with an average $\zeta$-potential of $16.4 \mathrm{mV}$ and an average size of $229.1 \mathrm{~nm}$, was able to show better diffusion in the vitreous and reach the inner limiting membrane (ILM) of the retina, thus overcoming the vitreous binding characteristic of cationic nanoparticles. In contrast, cationic albumin nanoparticles of $11.7 \mathrm{mV}$ $\zeta$-potential could not reach the retina and remained aggregated in the vitreous [58]. GC is a chitosan derivative in which glycol groups can mask its amine groups and result in antifouling effects, similar to those of 
PEG. It also exhibits superior plasma stability and long blood circulation. These properties possibly prevented the binding to the anionic vitreal surface, which cationic nanoparticles typically exhibit. In the same study, compared with these two, HA nanoparticles, whose size was $213.4 \mathrm{~nm}$ on average, showed efficient penetration across the retina as well as the vitreous. However, the intraretinal particles seemed to get eliminated faster as the retinal fluorescent intensity was reduced $72 \mathrm{~h}$ postinjection, compared with those of 6 and $24 \mathrm{~h}$ postinjection.

A combination of PEI/GC nanoparticles with an average size of $271.1 \mathrm{~nm}$ and a $\zeta$-potential of $+20.7 \mathrm{mV}$, accumulated on the ILM, and did not penetrate into the deeper retinal structures. These particles had properties more similar to GC particles than the PEI particles. HSA/GC heterogeneous nanoparticles had an average size of $293.3 \mathrm{~nm}$ size and $-1.9 \mathrm{mV} \zeta$-potential. Similar to the GC nanoparticles, the intravitreally administered HSA/GC nanoparticles accumulated on the ILM and could not penetrate into the deeper retinal structures. Blended HSA/HA nanoparticles were found to penetrate the whole retina structures and reach the outer retinal space.

Intravitreally administered PLA microparticles, encapsulating a hydrophilic drug molecule TG-0054, were found to retain their spherical shape even after 3 months in vivo release. Intact microparticles still containing the drug were found in the vitreous humor at the end of 1 and 3 months of in vivo release [50]. The particles were detectable in the vitreous humor after 3 months, but not in other ocular tissues, but significant drug levels were seen in choroid and retina. Significant drug levels were also found in the retina of the contralateral eye, possibly suggesting preferential binding to retina after systemic absorption. However, the bioactivity of the drug in the PLA particles is not known, since the peptide has been quantified in ocular tissues by LC/MS.

Bourges et al. [94] investigated the kinetics of PLA nanoparticle localization within the intraocular tissues after intravitreal injection, and the particles were found to be localized preferentially in the RPE for up to 4 months. Intravitreally injected albumin particles entrapping ganciclovir were found localized in the vitreous for up to 2 weeks after injection, and no adverse effects were observed on histological examination of the retina or other ocular tissues [53]

Intravitreally injected liposomes of different sizes and cholesterol composition were examined with a radiolabel for elimination kinetics by Barza et al. [35]. It was found that the rate of clearance was related to the size and not the cholesterol content in the liposomes, and that the elimination was probably via the anterior route. The presence of cholesterol was found to sustain the release of the encapsulated content in vitreous for a longer duration compared with non-cholesterol-loaded formulation. However, addition of cholesterol was not found to have any effect on the clearance of the vesicles from vitreous. This study also addressed the effect of vesicle size and disease state on the rate of clearance from the vitreous humor. It was found that small unilamellar vesicles of mean diameter $60 \mathrm{~nm}$ were eliminated more rapidly than large unilamelllar vesicles of $400 \mathrm{~nm}$ size, and that clearance was accelerated in the presence of inflammatory conditions in the eye.

Ocular distribution of liposomes encapsulating vasoactive intestinal peptide (VIP; a potent immunosuppressive neuropeptide) postintravitreal injection was examined by Camelo et al. using VIP-loaded fluorescent liposomes. The sizes of these liposomes were between 250 and $400 \mathrm{~nm}$ for Rh-Lip, and 300 and $600 \mathrm{~nm}$ for VIP-Rh-Lip [29]. After $24 \mathrm{~h}$ of intravitreal injection, the fluorescent liposomes were found localized in the posterior ocular tissues, and to a lesser extent, closer to the lens and ciliary body.

In vivo studies on treatment of various ocular diseases with the use of PLGA microparticles have reported no sign of retinal toxicity, nor significant inflammatory responses for periods of up to 2 months after intravitreal injections [25,95]. Similarly, intravitreal injection of microparticles of biodegradable PLA and PLGA encapsulating 5-fluorouracil was found to have no adverse effects on the ocular tissues [25] with the drug delivery being sustained for a week, and the microparticles themselves being cleared from vitreous by 48 days on average. PLGA undergoes hydrolysis to yield monomers of lactic acid and glycolic acid, which are then removed from the eye. At 14 days, faster clearance was seen in the vitreous cavity after vitrectomy, probably due to facilitated diffusion in the vitreous cavity.

Table 2 summarizes the nanoparticle properties which affect their vitreal transport and distribution.

\section{Carrier properties affecting periocular fate of carriers}

There are not many systematic studies on the disposition of periocularly injected particles and implants, but here we review the existing literature on the fate of periocular sustained-release formulations.

In a study by Amrite and Kompella, the size dependence on distribution of fluorescent polycarbonate nanoparticles of size 2000, 200 and $20 \mathrm{~nm}$ was studied [96], and the ocular disposition was examined. The 200 and $2000 \mathrm{~nm}$ particles were found to be retained at the subconjunctival space for up to 2 months postinjection. On the other hand, the $20 \mathrm{~nm}$ particles were 
rapidly cleared away by circulation, and only 15 and $8 \%$ of administered dose remained after 1 and 7 days, respectively. The role of the episcleral circulation, as a major route of clearance, was elucidated through these studies. Presence of inflammatory cells was observed in the ocular tissues, following the administration of 200 and $2000 \mathrm{~nm}$ particles, which were mostly retained at the site of administration.

In a study of subconjunctival budesonide delivery by PLA microparticles $(3.6 \mu \mathrm{m})$ versus nanoparticles $(345 \mathrm{~nm})$ [22], it was observed that microparticles were able to provide longer sustained delivery, up to a week, while the nanoparticles exhibited high burst, with the drug release rate declining more rapidly compared with the microparticles. Due to their sizes, both microparticles and nanoparticles are not expected to have any appreciable transport across the sclera, but to be retained at the site of administration (as per [96]). Biodegradable microparticles such as PLA or PLGA typically show low burst release and can provide longer sustained delivery compared with nanoparticles [22,24]. Microparticles of PLA were found to remain at periocular site of injection for up to 2 months, sustaining the release of TA postinjection, and found to retain their spherical shape [61]. Spherical microparticles remained entrapped in the tissue matrix at the site of injection after 2 months.

Intrascleral distribution of fluorescent nanoparticles by using hollow microneedles was studied by Jiang et al. [85] and they found that the nanoparticles were found distributed in the sclera while microparticles showed limited distribution. The nanospheres used in the study were made out of PLA, with an effective diameter of $278 \pm 13 \mathrm{~nm}$ and encapsulated Nile Red as a fluorescent marker within the particle. The microparticles used were latex, fluorescein-labeled microspheres of $1.0 \mu \mathrm{m}$ diameter. A kind of 'sieving effect' was observed, and nanoparticles were able to flow between scleral collagen fibrils, but microparticles were too big to pass through. The infusion of microparticles was facilitated only in the presence of enzymes such as collagenase or hyaluronidase, which were used to break down scleral collagen structure.

Liposome-bound LMWH was introduced subconjunctivally as a depot, and the ocular tissue concentrations were studied [34]. It was concluded by the authors that the longer sustained release obtained from the liposomal formulation is probably a combination of two factors: increased localization of the liposomes at the subconjunctival space, and intrascleral entrapment due to inability to traverse the sclera, and blocking of the lymphatic and other drainage paths by the liposomes thus reducing clearance of the free drug [97].

\section{Liposomal nanocarriers \& microcarriers and trans-scleral transport}

The characteristics of liposomes that enable them to form scleral depots have not been reported to date. Similarly, there are no reported data on the fate and distribution of liposomal carriers from subconjunctival depots. The authors of this article have observed, in an ex vivo setup using porcine sclera, the noninvasive depot-forming effect of certain liposomes which can be further extrapolated to loaded liposomes in an in vivo scenario. We describe the experimental setup and the formulation details below.

All experiments were performed after obtaining permission and approval from the Institutional Biosafety Committee at Nanyang Technological University. Porcine sclera was isolated and mounted in an Ussing chamber. Fluorescently tagged neutral liposomes prepared using 1-palmitoyl-2-oleoyl-sn-glycero-3-phosphocholine (POPC). Briefly, appropriate amounts of the lipid, along with fluorescently tagged lipid (1,2-dioleoyl-sn-glycero-3-phosphoethanolamine$\mathrm{N}$-(lissamine rhodamine B sulfonyl) (ammonium salt)) $(0.1 \mathrm{~mol} \%$ of total lipid) were weighed out into a round-bottom flask, and chloroform and methanol were added in the ratio of 2:1 and manually shaken until the lipids have dissolved. The solvent was then completely evaporated using a rotary evaporator $\left(\mathrm{IKA}^{\circledR}\right.$ RV 10, IKA ${ }^{\circledR}$ Werke GmbH \& Co. KG, Staufen, Germany), connected to a water bath (IKA ${ }^{\circledR} \mathrm{MB} 10$ basic, IKA ${ }^{\circledR}$ Werke $\mathrm{GmbH} \&$ Co.KG) maintained at $40^{\circ} \mathrm{C}$. The flask was rotated at $100 \times g$ r.p.m. under low pressure for an hour to eliminate any trace of residual solvent. The thin lipid film formed on the round bottom flask was hydrated with the phosphate-buffered saline, which leads to spontaneous formation of multilamellar vesicles (MLVs). The MLVs were then extruded sequentially through polycarbonate filters of different sizes fitted in a ben top extruder (Northern Lipids, Inc., BC, Canada) to obtain large unilamellar vesicles (LUVs) of desired sizes.

The fluorescently labeled liposome solutions were added to the donor chamber of the setup, which was in contact with the episcleral area of the tissue. The choroidal side was perfused with phosphate-buffered saline, with $0.05 \%$ sodium azide. Liposome transport was studied for 4 days, when noticeable differences in transport were observed. A schematic of the ex vivo transport setup used is shown in Figure 2.

For the study, we compared MLVs of average size $1000 \mathrm{~nm}$, LUVs of 94 and $73 \mathrm{~nm}$, for their effect on the transport. Following the transport experiment, the tissue sections were fixed in optimal cutting temperature compound (OCT), cryosectioned and imaged, to determine differences in localization of the differ- 
Table 2. Summary of nanoparticle properties affecting vitreal transport and distribution.

\begin{tabular}{|c|c|c|}
\hline Carrier property & Effect & Ref. \\
\hline Size & $\begin{array}{l}\text { Smaller particles }(50-200 \mathrm{~nm} \text { ) found to be able to reach the retina } \\
\text { postintravitreal injection. Vitreal clearance is also faster for smaller particles }\end{array}$ & {$[35,59]$} \\
\hline Charge & $\begin{array}{l}\text { Positively charged particles tend to remain clumped in the vitreous, } \\
\text { without diffusing, while anionic particles are able to diffuse to the retina }\end{array}$ & {$[57,58]$} \\
\hline PEG-ylation & PEGylated particles (even cationic) are able to diffuse to the retina & {$[57]$} \\
\hline $\begin{array}{l}\text { Ocular inflammatory } \\
\text { conditions }\end{array}$ & $\begin{array}{l}\text { Accelerated diffusion and clearance from vitreous in presence of } \\
\text { inflammatory conditions or vitrectomy }\end{array}$ & \\
\hline
\end{tabular}

ent liposomal formulations. Figure 3 shows the epifluorescence micrographs of the sclera, after transport experiments conducted with the fluorescently labeled liposomes. Even with passive diffusion of liposomes, a size-dependent difference in transport was observed. The larger sized MLVs (Figure 3A) are found to not exhibit significant intrascleral diffusion, while the LUVs exhibited a size-dependent transport into the sclera, with $73 \mathrm{~nm}$ liposomes (Figure 3C) exhibiting a higher transport into the sclera compared with the 94 nm liposomes (Figure 3B).

\section{Scleral implants}

In other work, the depot idea was pursued using a solid implant rather than an injection. For example, an intrascleral biodegradable implants made of PLA was used for sustained delivery of betamethasone phosphate for up to 8 weeks [43]. Complete degradation of

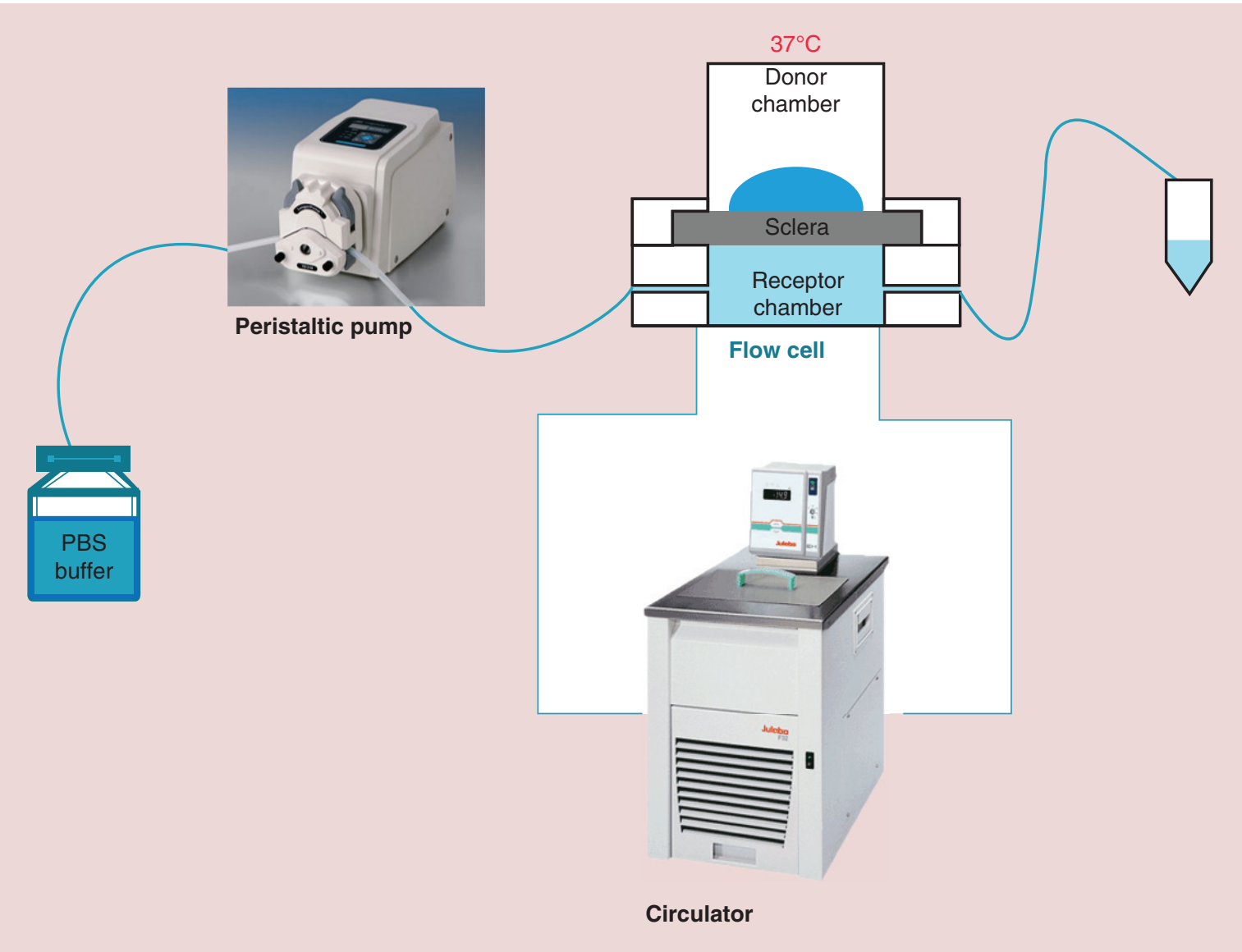

Figure 2. Schematic of the ex vivo experiment used for liposome scleral distribution studies. The sclera is mounted on a tissue mounting ring clamped between elastomer rings, between the donor and receiver chambers of the ex vivo setup. The entire flow cell is maintained at $37^{\circ} \mathrm{C}$ using a circulator water bath. The liposomal formulations to be tested are introduced in the donor chamber, and the receiver chamber is perfused with buffer using a peristaltic pump. 

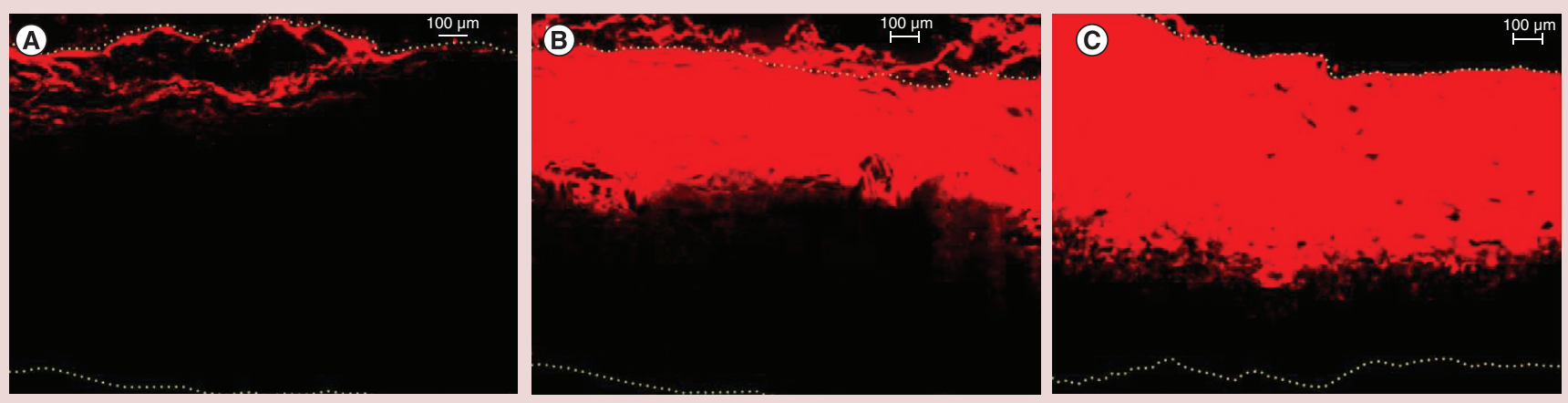

Figure 3. Representative epifluorescence micrographs showing the distribution of fluorescently tagged liposomes inside the sclera. (A) POPC MLV ( 1 1 $\mu \mathrm{m})$, (B) POPC LUV $(\sim 90 \mathrm{~nm})$ and (C) POPC LUV ( $70 \mathrm{~nm})$ for transport duration of 4 days ex vivo. The larger sized MLVs are found to not exhibit significant intrascleral diffusion, while the LUVs exhibited a size-dependent transport into the sclera, with the $73 \mathrm{~nm}$ liposomes exhibiting a higher transport into the sclera compared with the $94 \mathrm{~nm}$ liposomes. Dotted lines have been added to each image to more clearly indicate the upper and lower edges of the scleral tissue. Each experiment was repeated at least three-times.

LUV: Large unilamellar vesicle; MLV: Multilamellar vesicle; POPC: 1-Palmitoyl-2-oleoyl-sn-glycero-3-phosphocholine.

the implant was observed at 16 weeks after implantation, and no abnormalities were observed in the retina near the implantation site.

The biodegradability of subconjunctival implants was studied by Peng et al., and it was found to be dependent on the polymer characteristics. In particular, PLGA 50/50 microfilms and PLC 70/30 microfilms were compared, and found that the PLGA films had achieved almost complete degradation by month 4 and were not visible in histological sections while the PLC 70/30 persisted for up to 6 months [98]. However, no foreign body encapsulation of the implanted films was observed during the period of study, which is encouraging as these films can then potentially release their contents for a long duration, without displaying any toxicity, before degradation sets in.

In this study by Kim et al., using MRI contrast agents, the vitreous delivery from episcleral implants was examined [99]. It was found that in enucleated eyes, substantial concentrations were detected compared with live eyes, pointing to a big role played by dynamic barriers and circulatory systems, in clearing the drug from the episcleral location. These results are further confirmed by studies performed by Chan $e t a l$. which show a higher role of episcleral clearance than choroidal circulation for a drug delivered from a bioerodible subtenon implant in a rat model [42].

Biodegradable implants targeting the posterior segment of the eye have been shown to exhibit relatively low toxicity, and no adverse immunological reactions by both the intravitreal and subconjunctival routes. The main considerations would be the desired dura- tion of action, encapsulation efficiency achievable from the carrier systems, patient comfort and compliance from the particular system.

\section{Conclusion \& future perspective}

The current boost to ocular nanotherapies has been made possible largely due to increased collaborations between clinicians and material scientists in identifying specific clinical needs, which could be addressed by the tools of the material scientist, resulting in a high rate of translation to the clinic. However, sustained drug delivery to the posterior part of the eye remains an elusive target, in terms of clinical translation. Part of the reason is the lack of fundamental understanding of the transport, disposition and sustained-release mechanisms of the various nanomedicine approaches, in addition to toxicological effects in the eye. Although there have been numerous studies in the past few decades and many new systems have been explored for sustained release, the suitability of these systems for different clinical needs in the back of the eye remains to be fully explored. Properties of carrier materials such as biodegradability, time duration of release, burst and release mechanisms from the carriers, in addition to mode of administration, patient comfort and compliance, are distinguishing features of each carrier system.

Another factor to be considered in sustained-release systems in the eye is obscurement of vision by the carrier (injected or implanted). For example, the original Vitrasert implant was nonbiodegradable, with the sustained-release effect lasting only 1 month; the biostable implant could not be removed. For chronic administration of ganciclovir, new implants had to 
located carefully so as to not obscure vision. Similarly, the use of particles larger than about $300 \mathrm{~nm}$ is not desirable for injection into the vitreous; even more importantly, particles tend to aggregate readily in the vitreous and can lead to scattering of light and thus interfere with vision. This is not as critical as a factor when the injection is in the subconjunctival space. Nevertheless, it is preferred that the injected particle sizes remain below about $300 \mathrm{~nm}$, and that aggregation is minimized. In this context, loading of drug and its sustained release from nanoparticles assume major importance.

To achieve a reasonable duration of release/activity in the eye, enough drug has to be loaded into a small particle to last for a few weeks to months with one administration. Thus, the loading capacity (or how much drug can be effectively loaded into each nanocarrier system before administration) is of critical importance. This has tended to be the bottleneck in the practical translation of concept to the clinic.

In general, we believe that sustained efficacy of action in the posterior chamber may be achieved via subconjunctival injections of nanoparticles and microparticles, provided choroidal clearance of the bioactive is not high. Hydrogels have been evaluated for sustained release in the back of the eye, but only via intravitreal injections: in this regard, it is probably preferable to use a biodegradable implant rather than an intravitreally injected hydrogel, which may obscure vision depending on site of injection. However, biodegradable implant materials have to be selected very carefully for prolonged release of hydrophilic entities, such as antibodies and peptides or even siRNA.

Executive summary

Ocular anatomy and barriers to ocular delivery

- The peculiar anatomy of the eye poses several barriers to ocular drug delivery, which may be static/tissue barriers, circulatory and clearance systems as well as metabolic barriers.

- The main routes of ocular drug delivery are topical, systemic, intravitreal and periocular.

- For anterior segment disorders, topical route is the most common and least invasive. Systemic administration has limited efficacy due to the presence of blood-ocular barriers. Intravitreal injection can deliver therapeutic amounts to posterior ocular tissues, but is invasive. Periocular route is less invasive and proven successful in anterior segment diseases, but yet to be proven for posterior segment conditions.

Sustained anterior segment delivery

- For anterior segment disorders, sustained topical delivery systems are capable of improving corneal residence time from minutes to a few hours.

- For postsurgical inflammation management, several sustained-release formulations in the form of implants, films and liposomes have been developed.

- For glaucoma, we have reported the successful use of nanomedicine for sustained efficacy of action via the subconjunctival route in humans.

Sustained posterior segment delivery

- Main modes of posterior segment delivery: intravitreal and periocular.

- Sustained delivery is important due to chronic nature of most posterior segment disorders.

- Posterior segment sustained delivery systems that have been investigated include micro/nanoparticles, liposomes, composite systems, hydrogels, intraocular implants, intrascleral implants and other technologies such as microneedles, iontophoresis and trans-scleral ultrasound.

Carrier properties affecting disposition \& fate of therapeutics in the posterior ocular segment

- Fate of carrier postintravitreal injections has received attention, but not much is known of the fate of postperiocular administration.

- Postintravitreal injection, the size, charge and surface properties of carriers affect the fate, distribution and clearance of the therapeutics, in addition to the disease state.

- Not much research exists on the fate of periocularly administered carriers; size plays a role in clearance from periocular space, and micrometer-sized particles are found retained at the site of action for up to 2 months.

- Subconjunctivally injected depot-forming formulations can sustain the delivery of therapeutics over longer periods to avoid the need for repeated invasive injections.

Future perspective

- Fundamental understanding of the transport, disposition and sustained-release mechanisms warranted for the various nanomedicine systems, in the periocular space as well as in the posterior segment.

- Improvement of loading efficiency, without compromising on safety and toxicity of the formulations imperative.

- Minimally invasive approaches to sustained delivery systems addressing posterior ocular segment disorders are expected to gain more importance in the future. 
It must also be borne in mind that the actual, in vivo performance may be very different from the in vitro nanocarrier performance, due to the unique nature of the disease, presence of dynamic barriers to transport, clearance and circulatory systems, metabolic enzymes and the differential interaction with the tissues.

Thus, we conclude that a one-size-fits-all approach is not feasible or practical for sustained ocular delivery, due to the different drug-carrier interactions and different needs presented by each disease condition. Moreover, the posterior and anterior segments are different from each other, anatomically, and in terms of the diseases affecting them as well as the duration of treatment needed. Currently, one glaring medical need that has not yet been satisfactorily addressed is a minimally invasive approach to sustained delivery systems, addressing diseases in the back of the eye. Our approach to this is to manipulate the characteristics of nanocarriers and microcarriers to enable depot formation in the sclera followed by slow release of bioactives.

\section{References}

1 Rein DB, Wittenborn JS, Zhang X, Honeycutt AA, Lesesne $\mathrm{SB}$, Saaddine J. Forecasting age-related macular degeneration through the year 2050: the potential impact of new treatments. Arch. Ophthalmol. 127(4), 533-540 (2009).

2 Pascolini D, Mariotti SP. Global estimates of visual impairment: 2010. Br. J. Ophthalmol. 96(5), 614-618 (2011).

3 Geroski HD, Edelhauser FH. Drug delivery for posterior segment eye disease. Invest. Ophthalmol. Vis. Sci. 41(5), 961-964 (2000).

4 Chen JJ, Ebmeier SE, Sutherland WM, Ghazi NG. Potential penetration of topical ranibizumab (Lucentis) in the rabbit eye. Eye (Lond.) 25(11), 1504-1511 (2011).

5 Mains J, Wilson CG. The vitreous humor as a barrier to nanoparticle distribution. J. Ocul. Pharmacol. Ther. 29(2), 143-150 (2013).

6 Raghava S, Hammond M, Ub K. Periocular routes for retinal drug delivery. Expert Opin. Drug Deliv. 1(1), 99-114 (2004).

7 Urtti A. Challenges and obstacles of ocular pharmacokinetics and drug delivery. Adv. Drug Deliv. Rev. 58(11), 1131-1135 (2006).

8 Kim SH, GalbáN CJ, Lutz RJ et al. Assessment of subconjunctival and intrascleral drug delivery to the posterior segment using dynamic contrast-enhanced magnetic resonance imaging. Invest. Ophthalmol. Vis. Sci. 48(2), 808-814 (2007).

9 Almeida H, Amaral MH, Lobao P, Frigerio C, Sousa Lobo JM. Nanoparticles in ocular drug delivery systems for topical administration: promises and challenges. Curr. Pharm. Des. 21(36), 5212-5224 (2015).

10 Garty S, Shirakawa R, Warsen A et al. Sustained antibiotic release from an intraocular lens-hydrogel assembly for

\section{Acknowledgements}

The authors would like to acknowledge the use of histology and microscopy facilities at Singapore Eye Research Institute (SERI), Singapore.

\section{Financial \& competing interests disclosure}

The authors have no relevant affiliations or financial involvement with any organization or entity with a financial interest in or financial conflict with the subject matter or materials discussed in the manuscript. This includes employment, consultancies, honoraria, stock ownership or options, expert testimony, grants or patents received or pending, or royalties.

No writing assistance was utilized in the production of this manuscript.

\section{Open access}

This work is licensed under the Attribution-NonCommercialNoDerivatives 4.0 Unported License. To view a copy of this license, visit http://creativecommons.org/licenses/by-nc$\mathrm{nd} / 4.0 /$

cataract surgery. Invest. Ophthalmol. Vis. Sci. 52(9), 6109-6116 (2011).

11 Cholkar K, Patel SP, Vadlapudi AD, Mitra AK. Novel strategies for anterior segment ocular drug delivery. J. Ocul. Pharmacol. Ther. 29(2), 106-123 (2013).

12 Gulsen D, Chauhan A. Ophthalmic drug delivery through contact lenses. Invest. Ophthalmol. Vis. Sci. 45(7), 2342-2347 (2004).

13 Zimmer A, Kreuter J. Microspheres and nanoparticles used in ocular delivery systems. Adv. Drug Deliv. Rev. 16(1), 61-73 (1995).

14 Molokhia SA, Thomas SC, Garff KJ, Mandell KJ, Wirostko BM. Anterior eye segment drug delivery systems: current treatments and future challenges. J. Ocul. Pharmacol. Ther. 29(2), 92-105 (2013).

15 Natarajan JV, Darwitan A, Barathi VA et al. Sustained drug release in nanomedicine: a long-acting nanocarrier-based formulation for glaucoma. ACS Nano 8(1), 419-429 (2014).

16 Wong TT, Novack GD, Natarajan JV, Ho CL, Htoon HM, Venkatraman SS. Nanomedicine for glaucoma: sustained release latanoprost offers a new therapeutic option with substantial benefits over eyedrops. Drug Deliv. Transl. Res. 4(4), 303-309 (2014).

17 Cui LJ, Sun NX, Li XH, Huang J, Yang JG. Subconjunctival sustained release 5 -fluorouracil for glaucoma filtration surgery. Acta Pharmacol. Sin. 29(9), 1021-1028 (2008).

$18 \mathrm{Ng}$ XW, Liu KL, Veluchamy AB, Lwin NC, Wong TT, Venkatraman SS. A biodegradable ocular implant for longterm suppression of intraocular pressure. Drug Deliv. Transl. Res. 5(5), 469-479 (2015).

19 Ang M, Ng X, Wong C et al. Evaluation of a prednisolone acetate-loaded subconjunctival implant for the treatment of recurrent uveitis in a rabbit model. PLoS ONE 9(5), e97555 (2014). 
20 Ang M, Yan P, Zhen M, Foo S, Venkatraman SS, Wong TT. Evaluation of sustained release of PLC-loaded prednisolone acetate microfilm on postoperative inflammation in an experimental model of glaucoma filtration surgery. Curr. Eye Res. 36(12), 1123-1128 (2011).

21 Sampat KM, Garg SJ. Complications of intravitreal injections. Curr. Opin. Ophthalmol. 21(3), 178-183 (2010).

22 Kompella UB, Bandi N, Ayalasomayajula SP. Subconjunctival nano- and microparticles sustain retinal delivery of budesonide, a corticosteroid capable of inhibiting VEGF expression. Invest. Ophthalmol. Vis. Sci. 44(3), 1192-1201 (2003).

23 Bertram JP, Saluja SS, Mckain J, Lavik EB. Sustained delivery of timolol maleate from poly(lactic-co-glycolic acid)/poly(lactic acid) microspheres for over 3 months. J. Microencapsul. 26(1), 18-26 (2009).

24 Ayalasomayajula SP, Kompella UB. Subconjunctivally administered celecoxib-PLGA microparticles sustain retinal drug levels and alleviate diabetes-induced oxidative stress in a rat model. Eur. J. Pharmacol. 511(2-3), 191-198 (2005).

25 Moritera T, Ogura Y, Honda Y, Wada R, Hyon SH, Ikada Y. Microspheres of biodegradable polymers as a drug-delivery system in the vitreous. Invest. Ophthalmol. Vis. Sci. 32(6), 1785-1790 (1991).

26 Mishra Gyan P, Bagui M, Tamboli V, Mitra AK. Recent applications of liposomes in ophthalmic drug delivery. J. Drug Deliv. 2011, 863734 (2011).

27 Abrishami M, Ganavati SZ, Soroush D, Rouhbakhsh M, Jaafari MR, Malaekeh-Nikouei B. Preparation, characterization, and in vivo evaluation of nanoliposomesencapsulated bevacizumab (avastin) for intravitreal administration. Retina, J. Ret. Vit. Dis. 29(5), 699-703 (2009).

28 Barza M, Baum J, Szoka FJ. Pharmacokinetics of subconjunctival liposome-encapsulated gentamicin in normal rabbit eyes. Invest. Ophthalmol. Vis. Sci. 25(4), 486-490 (1984).

29 Camelo S, Lajavardi L, Bochot A et al. Ocular and systemic bio-distribution of rhodamine-conjugated liposomes loaded with VIP injected into the vitreous of Lewis rats. Mol. Vis. 13, 2263-2274 (2007).

30 Bochot A, Fattal E. Liposomes for intravitreal drug delivery: a state of the art. J. Control. Release 161(2), 628-634 (2012).

31 Gupta SK, Velpandian T, Dhingra N, Jaiswal J. Intravitreal pharmacokinetics of plain and liposome-entrapped fluconazole in rabbit eyes. J. Ocul. Pharmacol. Ther. 16(6), 511-518 (2000).

32 Fishman PH, Peymon GA, Lesar T. Intravitreal liposomeencapsulated gentamicin in a rabbit model. Invest. Ophthalmol. Vis. Sci. 27(7), 1103-1106 (1986).

33 Peyman GA, Khoobehi B, Tawakol M et al. Intravitreal injection of liposome-encapsulated ganciclovir in a rabbit model. Retina 7(4), 227-229 (1987).

34 Moon JW, Song YK, Jee JP, Kim CK, Choung HK, Hwang JM. Effect of subconjunctivally injected, liposome-bound, low-molecular-weight heparin on the absorption rate of subconjunctival hemorrhage in rabbits. Invest. Ophthalmol. Vis. Sci. 47(9), 3968-3974 (2006).
35 Barza M, Stuart M, Szoka F, Jr. Effect of size and lipid composition on the pharmacokinetics of intravitreal liposomes. Invest. Ophthalmol. Vis. Sci. 28, 893-900 (1987).

36 Ebrahim S, Peyman GA, Lee PJ. Applications of liposomes in ophthalmology. Surv. Ophthalmol. 50(2), 167-182 (2005).

37 Sanborn GE, Anand R, Torti RE et al. Sustained-release ganciclovir therapy for treatment of cytomegalovirus retinitis. Use of an intravitreal device. Arch. Ophthalmol. 110(2), 188-195 (1992).

38 Sakurai E, Nozaki M, Okabe K, Kunou N, Kimura H, Ogura Y. Scleral plug of biodegradable polymers containing tacrolimus (FK506) for experimental uveitis. Invest. Ophthalmol. Vis. Sci. 44(11), 4845-4852 (2003).

39 Driot JY, Novack GD, Rittenhouse KD, Milazzo C, Pearson PA. Ocular pharmacokinetics of fluocinolone acetonide after Retisert intravitreal implantation in rabbits over a 1-year period. J. Ocul. Pharmacol. Ther. 20(3), 269-275 (2004).

40 Sanford M. Fluocinolone acetonide intravitreal implant (Iluvien ${ }^{\circledR}$ ). Drugs 73(2), 187-193 (2013).

41 Carcaboso AM, Chiappetta DA, Opezzo JA et al. Episcleral implants for topotecan delivery to the posterior segment of the eye. Invest. Ophthalmol. Vis. Sci. 51(4), 2126-2134 (2010).

42 Chan JE, Pridgen TA, Csaky KG. Episcleral clearance of sodium fluorescein from a bioerodible sub-tenon's implant in the rat. Exp. Eye Res. 90, 501-506 (2010).

43 Okabe J, Kimura H, Kunou N, Okabe K, Kato A, Ogura Y. Biodegradable intrascleral implant for sustained intraocular delivery of betamethasone phosphate. Invest. Ophthalmol. Vis. Sci. 44(2), 740-744 (2003).

44 Okabe K, Kimura H, Okabe J, Kato A, Kunou N, Ogura Y. Intraocular tissue distribution of betamethasone after intrascleral administration using a nonbiodegradable sustained drug delivery device. Invest. Ophthalmol. Vis. Sci. 44(6), 2702-2707 (2003).

45 Gemenetzi M, Lotery AJ. Complement pathway biomarkers and age-related macular degeneration. Eye 30(1), 1-14 (2016).

46 Carrasquillo KG, Ricker JA, Rigas IK, Miller JW, Gragoudas ES, Adamis AP. Controlled delivery of the anti-VEGF Aptamer EYE001 with poly(lactic-co-glycolic)acid microspheres. Invest. Ophthalmol. Vis. Sci. 44(1), 290-299 (2003).

47 Pan CK, Durairaj C, Kompella UB et al. Comparison of long-acting bevacizumab formulations in the treatment of choroidal neovascularization in a rat model. J. Ocul. Pharmacol. Ther. 27(3), 219-224 (2011).

48 Li F, Hurley B, Liu Y, Leonard B, Griffith M. Controlled release of bevacizumab through nanospheres for extended treatment of age-related macular degeneration. Open Ophthalmol. J. 6, 54-58 (2012).

49 Varshochian R, Riazi-Esfahani M, Jeddi-Tehrani M et al. Albuminated PLGA nanoparticles containing bevacizumab intended for ocular neovascularization treatment. J. Biomed. Mater. Res. A 103(10), 3148-3156 (2015).

50 Shelke NB, Kadam R, Tyagi P, Rao VR, Kompella UB. Intravitreal poly(L-lactide) microparticles sustain retinal and 
choroidal delivery of TG-0054, a hydrophilic drug intended for neovascular diseases. Drug Deliv. Transl. Res. 1(1), 76-90 (2011).

Zhang L, Li Y, Zhang C, Wang Y, Song C. Pharmacokinetics and tolerance study of intravitreal injection of dexamethasone-loaded nanoparticles in rabbits. Int. J. Nanomedicine 4, 175-183 (2009).

52 Cardillo JA, Souza-Filho AA, Oliveira AG. Intravitreal bioerudivel sustained-release triamcinolone microspheres system (RETAAC). Preliminary report of its potential usefulness for the treatment of diabetic macular edema. Arch. Soc. Esp. Oftalmol. 81(12), 675-677, 679-681 (2006).

53 Merodio M, Irache JM, Valamanesh F, Mirshahi M. Ocular disposition and tolerance of ganciclovir-loaded albumin nanoparticles after intravitreal injection in rats. Biomaterials 23(7), 1587-1594 (2002).

54 Honda M, Asai T, Umemoto T, Araki Y, Oku N, Tanaka M. Suppression of choroidal neovascularization by intravitreal injection of liposomal SU5416. Arch. Ophthalmol. 129(3), 317-321 (2011).

55 Maurice D. Review: practical issues in intravitreal drug delivery. J. Ocul. Pharmacol. Ther. 17(4), 393-401 (2001).

56 Li X, Li L, Zhang Z, Chen H. An overview on pharmacokinetics, disposition, and safety of nanoparticles in ocular applications. Curr. Drug Metab. 14(8), 857-862 (2013).

57 Koo $\mathrm{H}$, Moon $\mathrm{H}$, Han $\mathrm{H}$ et al. The movement of self-assembled amphiphilic polymeric nanoparticles in the vitreous and retina after intravitreal injection. Biomaterials 33(12), 3485-3493 (2012).

Kim H, Robinson SB, Csaky KG. Investigating the movement of intravitreal human serum albumin nanoparticles in the vitreous and retina. Pharm. Res. 26(2), 329-337 (2009).

59 Sakurai E, Ozeki H, Kunou N, Ogura Y. Effect of particle size of polymeric nanospheres on intravitreal kinetics. Ophthalmic Res. 33(1), 31-36 (2001).

60 Stern WH, Heath TD, Lewis GP et al. Clearance and localization of intravitreal liposomes in the aphakic vitrectomized eye. Invest. Ophthalmol. Vis. Sci. 28(5), 907-911 (1987)

61 Kadam RS, Tyagi P, Edelhauser HF, Kompella UB. Influence of choroidal neovascularization and biodegradable polymeric particle size on transscleral sustained delivery of triamcinolone acetonide. Int. J. Pharm. 434, 140-147 (2012).

62 Kang SJ, Durairaj C, Kompella UB, O'brien JM, Grossniklaus HE. Subconjunctival nanoparticle carboplatin in the treatment of murine retinoblastoma. Arch. Ophthalmol. 127(8), 1043-1047 (2009).

63 Brown DM, Kaiser PK, Michels M et al. Ranibizumab versus verteporfin for neovascular age-related macular degeneration. N. Engl. J. Med. 355(14), 1432-1444 (2006).

64 Le Bourlais C, Chevanne F, Ropert P et al. Release kinetics of liposome-encapsulated ganciclovir after intravitreal injection in rabbits. J. Microencapsul. 13(4), 473-480 (1996).

65 Zhang R, He R, Qian J, Guo J, Xue K, Yuan YF. Treatment of experimental autoimmune uveoretinitis with intravitreal

injection of tacrolimus (FK506) encapsulated in liposomes. Invest. Ophthalmol. Vis. Sci. 51(7), 3575-3582 (2010).

66 for retinal disorders progress to date. Drugs Aging 27(2), 117-134 (2010).

67 Yandrapu SK, Upadhyay AK, Petrash JM, Kompella UB. Nanoparticles in porous microparticles prepared by supercritical infusion and pressure quench technology for sustained delivery of bevacizumab. Mol. Pharm. 10(12), 4676-4686 (2013).

68 Elsaid N, Jackson TL, Elsaid Z, Alqathama A, Somavarapu S. PLGA microparticles entrapping chitosan-based nanoparticles for the ocular delivery of ranibizumab. Mol. Pharm. 13(9), 2923-2940 (2016).

69 Osswald CR, Kang-Mieler JJ. Controlled and extended in vitro release of bioactive anti-vascular endothelial growth factors from a microsphere-hydrogel drug delivery system. Curr. Eye Res. 41(9), 1216-1222 (2016).

70 Hirani A, Grover A, Lee YW, Pathak Y, Sutariya V. Triamcinolone acetonide nanoparticles incorporated in thermoreversible gels for age-related macular degeneration. Pharm. Dev. Technol. 21(1), 61-67 (2016).

71 Peptu CA, Popa M, Savin C, Popa RF, Ochiuz L. Modern drug delivery systems for targeting the posterior segment of the eye. Curr. Pharm. Des. 21(42), 6055-6069 (2015).

72 Yu Y, Lau LCM, Lo ACY, Chau Y. Injectable chemically crosslinked hydrogel for the controlled release of bevacizumab in vitreous: a 6 -month in vivo study. Transl. Vis. Sci. Technol. 4(2), 5 (2015).

73 Rauck BM, Friberg TR, Medina Mendez CA et al. Biocompatible reverse thermal gel sustains the release of intravitreal bevacizumab in vivo. Invest. Ophthalmol. Vis. Sci. 55(1), 469-476 (2014).

74 Hu CC, Chaw JR, Chen CF, Liu HW. Controlled release bevacizumab in thermoresponsive hydrogel found to inhibit angiogenesis. Biomed. Mater. Eng. 24(6), 1941-1950 (2014).

75 Wang $\mathrm{CH}$, Hwang YS, Chiang PR, Shen CR, Hong WH, Hsiue GH. Extended release of bevacizumab by thermosensitive biodegradable and biocompatible hydrogel. Biomacromolecules 13(1), 40-48 (2012).

76 Lovett ML, Wang X, Yucel T et al. Silk hydrogels for sustained ocular delivery of anti-vascular endothelial growth factor (anti-VEGF) therapeutics. Eur. J. Pharm. Biopharm. 95(Pt B), 271-278 (2015).

77 Tyagi P, Barros M, Stansbury JW, Kompella UB. Light activated, in situ forming gel for sustained suprachoroidal delivery of bevacizumab. Mol. Pharm. 10 (8), 2858-2867 (2013).

78 Tsui JY, Dalgard C, Van Quill KR et al. Subconjunctival topotecan in fibrin sealant in the treatment of transgenic murine retinoblastoma. Invest. Ophthalmol. Vis. Sci. 49(2), 490-496 (2008).

79 Gilbert JA, Simpson AE, Rudnick DE, Geroski DH, Aaberg TMJ, Edelhauser HF. Transscleral permeability and intraocular concentrations of cisplatin from a collagen matrix. J. Control. Release 89, 409-417 (2003). 
80 Misra GP, Singh RSJ, Aleman TS, Jacobson SG, Gardner TW, Lowe TL. Subconjunctivally implantable hydrogels with degradable and thermoresponsive properties for sustained release of insulin to the retina. Biomaterials 30(33), 6541-6547 (2009).

81 Rieke ER, Amaral J, Becerra SP, Lutz RJ. Sustained subconjunctival protein delivery using a thermosetting gel delivery system. J. Ocul. Pharmacol. Ther. 26(1), 55-64 (2010).

82 Christoforidis JB, Chang S, Jiang A, Wang J, Cebulla $\mathrm{CM}$. Intravitreal devices for the treatment of vitreous inflammation. Mediators Inflamm. 2012, 8 (2012).

83 Patel SR, Berezovsky DE, Mccarey BE, Zarnitsyn V, Edelhauser HF, Prausnitz MR. Targeted administration into the suprachoroidal space using a microneedle for drug delivery to the posterior segment of the eye. Invest. Ophthalmol. Vis. Sci. 53(8), 4433-4441 (2012).

84 Patel SR, Lin AS, Edelhauser HF, Prausnitz MR. Suprachoroidal drug delivery to the back of the eye using hollow microneedles. Pharm. Res. 28(1), 166-176 (2011).

85 Jiang J, Moore JS, Edelhauser HF, Prausnitz MR. Intrascleral drug delivery to the eye using hollow microneedles. Pharm. Res. 26(2), 395-403 (2009).

86 Tao W. Application of encapsulated cell technology for retinal degenerative diseases. Expert Opin. Biol. Ther. 6(7), $717-726$ (2006).

87 Humayun M, Santos A, Altamirano JC et al. Implantable micropump for drug delivery in patients with diabetic macular edema. Transl. Vis. Sci. Technol. 3(6), 5 (2014).

88 Gutiérrez-Hernández JC, Caffey S, Abdallah W et al. Oneyear feasibility study of replenish micropump for intravitreal drug delivery: a pilot study. Transl. Vis. Sci. Technol. 3(4), 8 (2014).

89 Lee SS, Hughes P, Ross AD, Robinson MR. Biodegradable implants for sustained drug release in the eye. Pharm. Res. 27, 2043-2053 (2010).
90 De Campos AM, Diebold Y, Carvalho ELS, SáNchez A, Alonso MJ. Chitosan nanoparticles as new ocular drug delivery systems: in vitro stability, in vivo fate, and cellular toxicity. Pharm. Res. 21(5), 803-810 (2004).

91 Boruchoff SA, Woodin AM. Viscosity and composition of solutions derived from rabbit vitreous humour. Br. J. Ophthalmol. 40(2), 113-118 (1956).

92 Amrite AC, Edelhauser HF, Singh SR, Kompella UB. Effect of circulation on the disposition and ocular tissue distribution of $20 \mathrm{~nm}$ nanoparticles after periocular administration. Mol. Vis. 14, 150-160 (2008).

$93 \mathrm{Xu} \mathrm{J}$, Heys JJ, Barocas VH, Randolph TW. Permeability and diffusion in the vitreous humor: implications for drug delivery. Pharm. Res. 17(6), 664-669 (2000).

94 Bourges JL, Gautier SE, Delie F et al. Ocular drug delivery targeting the retina and retinal pigment epithelium using polylactide nanoparticles. Invest. Ophthalmol. Vis. Sci. 44(8), 3562-3569 (2003)

95 Giordano GG, Chevez-Barrios P, Refojo MF, Garcia $\mathrm{CA}$. Biodegradation and tissue reaction to intravitreous biodegradable poly(D,L-lactic-co-glycolic)acid microspheres. Curr. Eye Res. 14(9), 761-768 (1995).

96 Amrite AC, Kompella UB. Size-dependent disposition of nanoparticles and microparticles following subconjunctival administration. J. Pharm. Pharmacol. 57, 1555-1563 (2005).

97 Assil KK, Hartzer M, Weinreb RN, Nehorayan M, Ward T, Blumenkranz M. Liposome suppression of proliferative vitreoretinopathy. Rabbit model using antimetabolite encapsulated liposomes. Invest. Ophthalmol. Vis. Sci. 32(11), 2891-2897 (1991)

98 Peng Y, Ang M, Foo S et al. Biocompatibility and biodegradation studies of subconjunctival implants in rabbit eyes. PLoS ONE 6(7), e22507 (2011).

99 Kim SH, Csaky KG, Wang NS, Lutz RJ. Drug elimination kinetics following subconjunctival injection using dynamic contrast-enhanced magnetic resonance imaging. Pharm. Res. 25(3), 512-520 (2008). 